Redglobe grapes withstood water loss better than other cultivars before exhibiting signs of damage.

\title{
Table grapes suffer water loss, stem browning during cooling delays
}

\author{
Carlos H. Crisosto 」 Joe L. Smilanick 」 Nick K. Dokoozlian
}

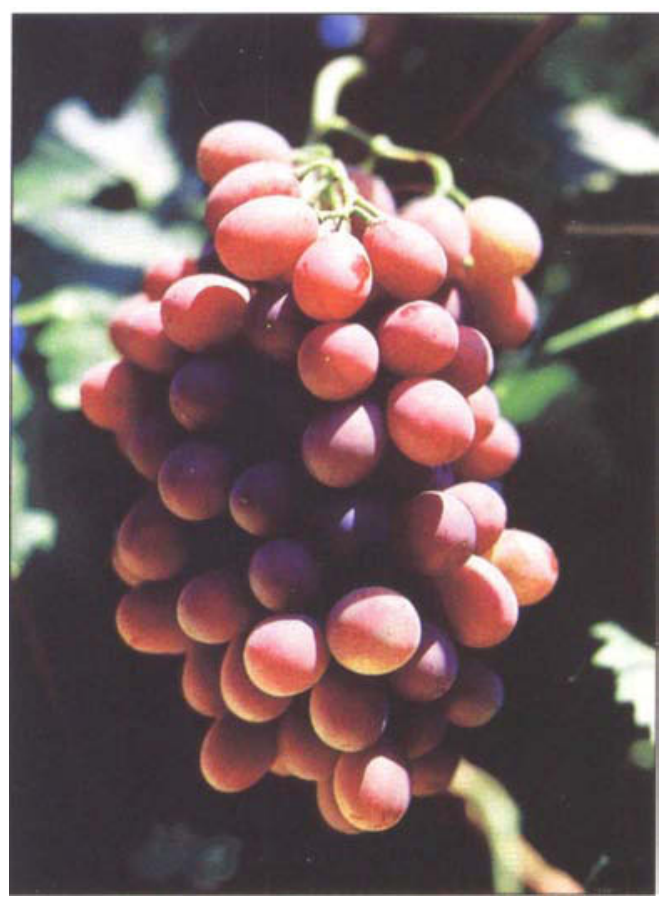

The water loss in table grapes that occurs during postharvest handling can lead to stem browning, berry shatter, and wilting and shriveling of the fruit. Critical grape cluster water-loss threshold values for stem browning were determined for Perlette, Thompson Seedless, Flame Seedless, Fantasy Seedless and Redglobe table grape cultivars. Fantasy Seedless and Redglobe withstood higher levels of stem water loss than Perlette, Flame Seedless and Thompson Seedless before expressing moderate to severe stem browning. Our survey of potential cluster water loss during harvesting operations indicated that a short cooling delay at high air temperatures contributed to stem browning. These low critical cluster water-loss threshold values combined with the high level of water loss measured during harvesting operations illustrate the need to minimize cooling delays and the importance of developing a technique to reduce cluster water loss during harvest and/or postharvest handling. The use of cluster bags and foam boxes reduced grape cluster water loss during harvest operations.
$\mathrm{T}$ able grapes are a nonclimacteric fruit with a low rate of physiological activity, but they are subject to serious water losses during postharvest handling. Rachis (axis bearing berries) browning, which occurs as a consequence of water loss, reduces table grape postharvest quality (Cappellini et al. 1986). Cumulative water losses occurring during postharvest handling may lead to stem browning, berry shatter, and wilting and shriveling of berries during marketing.

We conducted a series of experiments in the F. Gordon Mitchell Postharvest Building at Kearney Agricultural Center in Parlier to determine the relationship between cluster water loss and rachis browning for the major table grape cultivars. Our second goal was to survey the magnitude of cluster water losses occurring during commercial table grape harvesting operations in California.

Perlette, Thompson Seedless, Flame Seedless, Fantasy Seedless and Redglobe table grapes were grown at the same location using standard commercial practices. In all of the experiments, we used a completely randomized design, but with different numbers of replications ( 6 to 20 ). The data was subjected to analysis of variance (ANOVA) prior to a least significant differences (LSD) means separation using the SAS program.

\section{Water loss and stem browning}

All table grape cultivars were harvested at commercial maturity based on percentage of soluble solids concentration (SSC). Clusters (berries + stems) were forced to lose $1.0 \%, 1.5 \%$, $2.0 \%, 2.5 \%, 3.0 \%, 3.5 \%, 4.0 \%, 4.5 \%$ or $5.0 \%$ water by weight. This was done by holding them for different time periods at $79^{\circ} \mathrm{F}, 30 \%$ relative humidity (rh) and an air velocity of approximately 25 feet per minute (fpm) to simulate environmental conditions during cooling delays. Cluster water loss was measured by weighing the clusters at harvest and then reweighing them periodically until the targeted percent water loss was reached.

Immediately after these different delay periods, grapes were placed in cold storage at $32^{\circ} \mathrm{F}, 95 \%$ rh and an air velocity of approximately $12 \mathrm{fpm}$. We used 20 clusters from each cultivar for each targeted water-loss percentage during each simulated cooling-delay period. Cluster water loss was calculated as a percentage of its fresh (harvest) weight. Table grape stem color and berry appearance were determined after cooling and then daily during the cold storage period. Stem browning symptoms were evaluated using the following scoring system: healthy = entire stem including the cap stems (merging point between ber- 
ries and rachis) green and healthy; slight $=$ only cap stems showing browning; moderate = cap stems and secondary stems showing browning; and severe = cap stems, secondary stems and primary stems completely brown.

After the subjective evaluation of berry and stem condition, the berries and stems were separated. The stems were weighed (fresh weight) and then dried in a standard drying oven at $158^{\circ} \mathrm{F}$ for at least 10 days. After drying, the stems were reweighed (stem dry weight). We calculated stem water loss based on the stem water content. (See box below for equations.)

\section{Water loss after harvest}

Cluster water loss of grapes packed in corrugated, TKV (Technical Kraft Veneer $)$, and foam boxes $(17.5 \times 14 \times$
7.5 inches) was measured after different cooling delay periods $(0,4$ or 8 hours) on three different dates. Ten boxes of Flame Seedless grapes were harvested and packed with or without standard polyethylene cluster bags. After the grapes were packed, the boxes were exposed to the sun by placing them in a single layer on the ground for different time periods to simulate cooling delays. We conducted a test to study the relationship between box material, cluster bags and cluster water loss during a 4-hour afternoon cooling delay. During all of these trials, air temperature was monitored hourly using a Campbell 21-X data logger. Cluster water loss was determined for 10 boxes per treatment after the different cooling delay periods. Fruit stem condition of these fruit was evaluated after 7 days cold stor-

Stem water content was determined after each visual evaluation: stem fresh weight at evaluation - stem dry weight $\times 100 \%$.

Stem water loss (\%) was calculated as:

mean harvest stem water content - stem water content at evaluation mean harvest stem water content

TABLE 1. Relationship between grape cluster water loss and visual stem browning after cooling delays $\left(79^{\circ} \mathrm{F}, 30 \%\right.$ relative humidity [rh] and 25 feet per minute [fpm] air velocity) followed by 7 days cold storage $\left(32^{\circ} \mathrm{F}, 95 \%\right.$ rh and a $10 \mathrm{fpm}$ air velocity)

\begin{tabular}{|c|c|c|c|c|c|}
\hline \multirow[b]{2}{*}{$\begin{array}{l}\text { Visual stem } \\
\text { browning symptoms* }\end{array}$} & \multicolumn{5}{|c|}{ Cluster water loss } \\
\hline & Perlette & $\begin{array}{l}\text { Flame } \\
\text { Seedless }\end{array}$ & $\begin{array}{l}\text { Thompson } \\
\text { Seedless }\end{array}$ & $\begin{array}{l}\text { Fantasy } \\
\text { Seedless }\end{array}$ & Redglobe \\
\hline & & & $\%$ & ........ & (n........ \\
\hline Slight & 2.0 & 2.2 & 2.2 & 2.3 & 2.5 \\
\hline Moderate & 2.6 & 2.8 & 2.7 & 3.1 & 3.3 \\
\hline Severe & 3.3 & 3.3 & 3.6 & 3.8 & 4.1 \\
\hline $\operatorname{LSD}_{0.05}$ & 0.4 & 0.3 & 0.2 & 0.6 & 0.3 \\
\hline
\end{tabular}

"Symptoms: Slight = only cap stems showing browning; moderate = cap stems and secondary stems showing browning; and severe = cap stems, secondary and primary stems fully brown.

LSD $=$ Least Significant Differences

TABLE 2. Relationship between grape stem water loss and visual browning symptoms after cooling delays $\left(79^{\circ} \mathrm{F}, 30 \%\right.$ rh and $25 \mathrm{fpm}$ air velocity) followed by 7 days cold storage $\left(32^{\circ} \mathrm{F}, 95 \%\right.$ rh and a $10 \mathrm{fpm}$ air velocity)

\begin{tabular}{|c|c|c|c|c|c|}
\hline \multirow[b]{2}{*}{$\begin{array}{l}\text { Visual stem } \\
\text { browning symptoms* }\end{array}$} & \multicolumn{5}{|c|}{ Stem water loss } \\
\hline & Perlette & $\begin{array}{c}\text { Flame } \\
\text { Seedless }\end{array}$ & $\begin{array}{l}\text { Thompson } \\
\text { Seedless }\end{array}$ & $\begin{array}{l}\text { Fantasy } \\
\text { Seedless }\end{array}$ & Redglobe \\
\hline & \multicolumn{5}{|c|}{ (n) } \\
\hline Slight & 16.5 & 14.4 & 15.1 & 20.2 & 23.8 \\
\hline Moderate & 24.8 & 21.6 & 22.6 & 24.5 & 35.6 \\
\hline Severe & 33.0 & 28.8 & 27.7 & 40.4 & 47.4 \\
\hline $\mathrm{LSD}_{0.05}$ & 7.8 & 6.5 & 4.3 & 4.1 & 9.4 \\
\hline
\end{tabular}

-Symptoms: Slight = only cap stems showing browning, moderate = cap stems and secondary stems showing browning, and severe = cap stems, secondary and primary stems fully brown.

LSD $=$ Least Significant Differences

age $\left(32^{\circ} \mathrm{F}, 95 \%\right.$ rh and $10 \mathrm{fpm}$ air velocity). Cluster water loss was calculated by weighing grape clusters immediately at harvest and then reweighing at the end of each field cooling delay. Grape cluster water loss is expressed as a percentage of the harvest weight.

\section{Stem browning related to water}

For the five table grape cultivars evaluated, visual stem browning symptoms were significantly related to cluster water loss. Clusters showing severe stem browning symptoms lost more water than clusters with moderate and slight stem browning symptoms (table 1). Also, clusters with moderate stem browning symptoms lost more water than clusters showing only slight stem browning symptoms. The first visible symptoms of stem dehydration during cold storage were observed on Perlette, Flame Seedless and Thompson Seedless table grapes when cluster water loss (berries + stems) reached $2.0 \%$ to $2.2 \%$ and when Fantasy Seedless and Redglobe cluster water loss reached $2.3 \%$ to $2.5 \%$ (table 1). In general, Perlette, Flame Seedless and Thompson Seedless showed more advanced stem browning symptoms than the other cultivars at the same percentage cluster water loss. For example, Perlette, Flame Seedless and Thompson Seedless showed moderate stem browning symptoms when cluster water loss reached $2.6 \%, 2.8 \%$ and $2.7 \%$, respectively, while the same symptoms were not present on Fantasy Seedless and Redglobe until water loss exceeded $3.0 \%$. Cluster water loss of $4.6 \%$ was necessary to induce berry shriveling in these cultivars (data not shown).

Cultivar genotype also influenced the length of time it took for stem browning to develop during cold storage. Thompson Seedless and Flame Seedless clusters that lost $2.0 \%$ water during a cooling delay took 2 and 4 days of cold storage, respectively, to exhibit cap stem browning (data not shown).

Development of visual stem browning symptoms was also significantly related to stem water loss. Stems with slight browning symptoms had lost less of their harvest fresh weight than 
stems with moderate and severe symptoms (table 2). Also, stems with moderate symptoms had lost less of their harvest fresh weight than stems showing severe symptoms. Perlette, Flame Seedless and Thompson Seedless stems had to lose $16.5 \%, 14.4 \%$ and $15.1 \%$, respectively, of their water content before showing cap stem dehydration symptoms. Fantasy Seedless and Redglobe stems needed to lose more than $20 \%$ of their water content before showing cap stem dehydration symptoms (table 2). Redglobe stems had moderate to severe stem browning after losing $36 \%$ of their water content. Perlette, Flame Seedless, Thompson Seedless and Fantasy Seedless had moderate to severe stem browning symptoms when they lost more than $25 \%$ of their stem water content. The fact that Flame Seedless grapes were the first to show dehydration symptoms with $14 \%$ stem water loss indicates that this cultivar is more sensitive to stem browning than the others. In contrast, Fantasy Seedless and Redglobe experienced higher levels of stem water loss than Perlette, Flame Seedless and Thompson Seedless be-

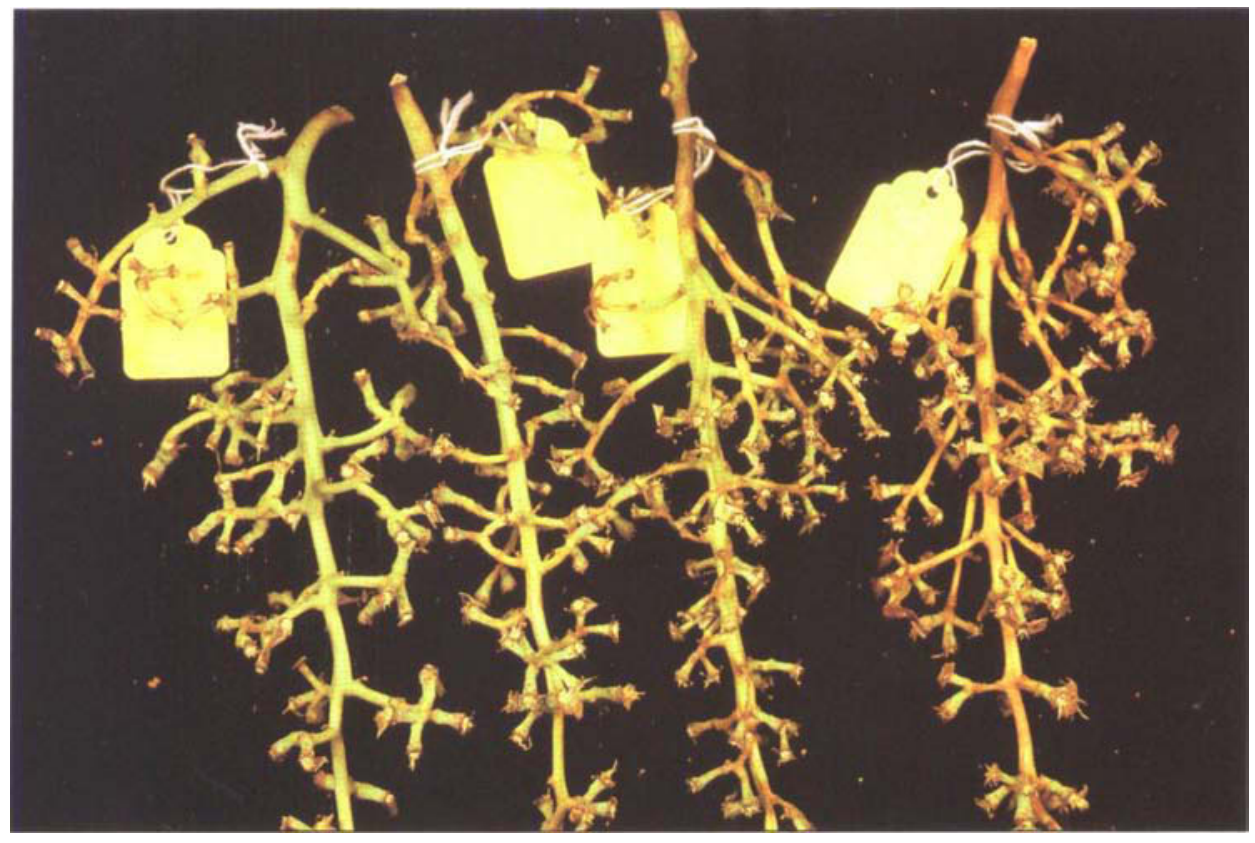

Flame Seedless table grape stem condition after $0,3,6$ and 9 hours delayed cooling $\left(79^{\circ} \mathrm{F}, 30 \%\right.$ rh and $25 \mathrm{fpm}$ air velocity) followed by 7 days cold storage ( $32^{\circ} \mathrm{F}, 95 \% \mathrm{rh}$ and $10 \mathrm{fpm}$ air velocity). fore expressing moderate to severe stem browning symptoms.

\section{Survey of cluster water losses}

Postharvest water loss from Flame Seedless table grapes was influenced by temperature and the length of the
TABLE 3. Influence of postharvest cooling delays on cluster water loss of bulk packed Flame Seedless table grapes in three box materials (survey)

\begin{tabular}{|c|c|c|c|c|}
\hline \multirow[b]{3}{*}{ Box material } & \multicolumn{4}{|c|}{ Cluster water loss during cooling delays* } \\
\hline & \multirow{2}{*}{$\begin{array}{c}\text { Trial } 1 \\
\text { Full Day } \\
\text { (8 hours) }\end{array}$} & \multicolumn{2}{|c|}{ Trial 2} & \multirow{2}{*}{$\begin{array}{l}\text { Trial } 3 \\
\text { Afternoon } \\
\text { ( } 4 \text { hours) }\end{array}$} \\
\hline & & $\begin{array}{l}\text { Morning } \\
\text { (4 hours) }\end{array}$ & $\begin{array}{l}\text { Afternoon } \\
\text { (4 hours) }\end{array}$ & \\
\hline & & & & $\ldots \ldots$ \\
\hline Corrugated & 1.38 & 0.23 & 0.92 & 0.81 \\
\hline TKV & 0.99 & 0.20 & 0.70 & 0.63 \\
\hline Foam & 0.81 & 0.19 & 0.47 & 0.59 \\
\hline $\mathrm{LSD}_{005}$ & 0.28 & 0.08 & 0.20 & 0.15 \\
\hline
\end{tabular}

-Trials were carried out on three different dates.

LSD $=$ Least Significant Differences

TABLE 4. Influence of box material and cluster bags on cluster water loss and stem condition of Flame Seedless table grapes measured after a 4-hour cooling delay and 7 days cold storage

\begin{tabular}{llccc}
\hline & \multicolumn{3}{c}{ Water loss } \\
\cline { 2 - 5 } Box material & Cluster bag & $\begin{array}{c}\text { After field delay } \\
\text { (4-hours) }\end{array}$ & $\begin{array}{c}\text { After field delay plus } \\
\text { cold storage (7 days } \\
\text { at } 32{ }^{\circ} \mathbf{F} / 80 \% \text { rh) }\end{array}$ & $\begin{array}{c}\text { Stem browning } \\
\text { (after field delay } \\
\text { plus cold storage) }\end{array}$ \\
\hline Corrugated & No & 0.96 & 2.40 & 1.79 \\
Corrugated & Yes & 0.87 & 2.21 & slight \\
TKV & No & 0.82 & 1.81 & slight \\
TKV & Yes & 0.57 & 1.86 & slight \\
Foam & No & 0.48 & 1.35 & slight \\
Foam & Yes & 0.46 & 0.35 & - \\
LSD & - & 0.12 & & - \\
\hline
\end{tabular}

"Cap stems showing browning.

LSD $=$ Least Significant Differences cooling delay. After an 8-hour field delay (Trial 1), Flame Seedless grape water loss reached $1.38 \%$ (table 3 ). A minimum of $0.19 \%$ and a maximum of $0.92 \%$ water loss were measured after a 4-hour field delay (Trials 2 and 3). Because we used a one-box tier placed directly in the sun during the different cooling delay periods, these water-loss values represent the maximum potential for cluster water loss under these environmental conditions.

Box materials and cluster bags influenced the amount of water lost during the cooling delay period (table 4). In general, grapes packed in corrugated boxes lost more water than grapes packed in TKV boxes, while grapes packed in TKV boxes lost more water than grapes packed in foam. Larger differences occurred between corrugated and foam boxes than be-

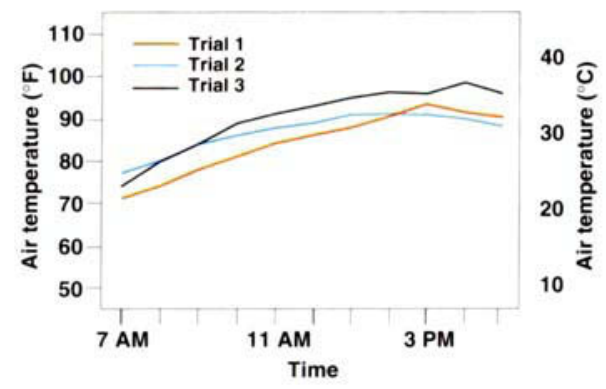

Fig. 1. Average air temperatures during table grape harvests. 


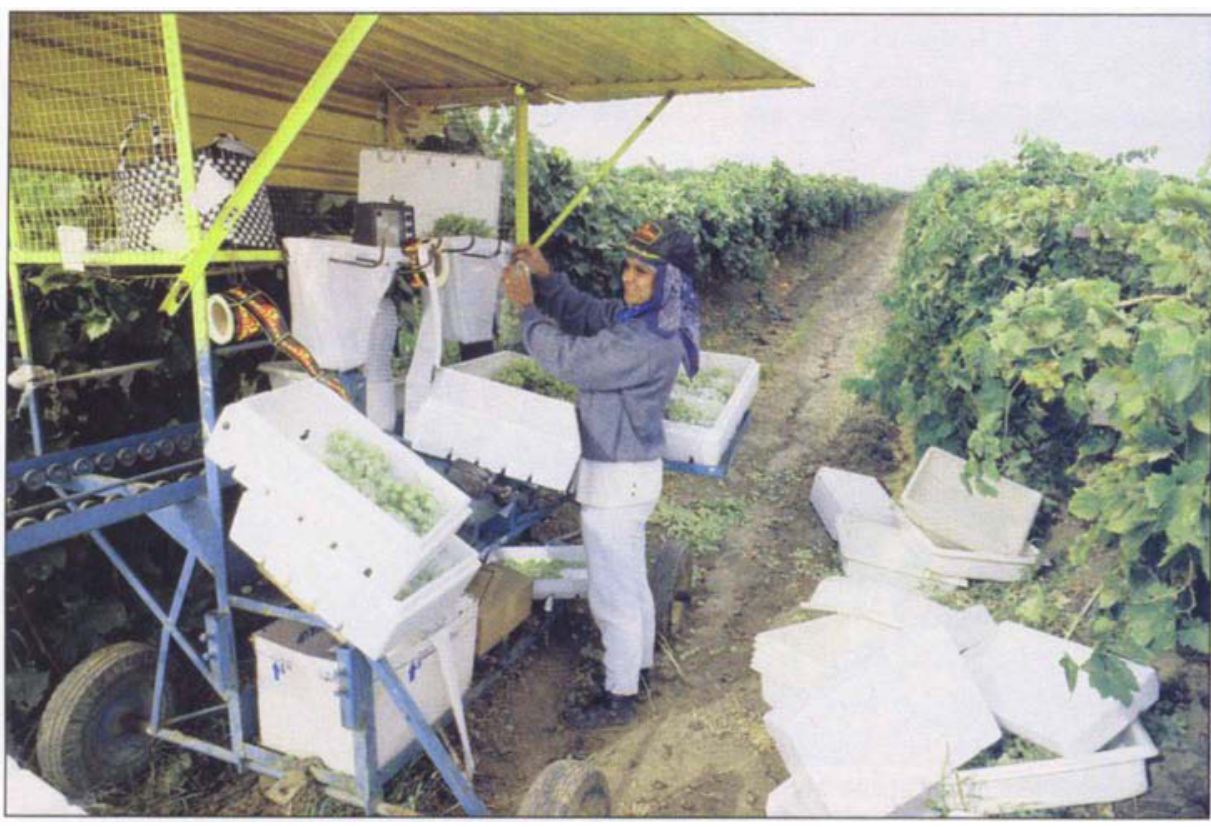

Field packaging of Thompson Seedless table grapes in California.

tween TKV and foam boxes. The greatest water loss during this cooling-delay period $(0.96 \%)$ was measured in grapes packed in corrugated boxes with and without cluster bags (bulk). Bagged grapes packed in foam boxes lost the least amount of water $(0.46 \%)$ during this field delay period. The use of cluster bags reduced water losses in all three of the containers tested. The table grapes continued to lose water during fumigation, forced-air cooling and 7 days cold storage $\left(32^{\circ} \mathrm{F} / 80 \% \mathrm{rh}\right)$. When evaluated at the end of cold storage, only the fruit packed in the foam boxes with cluster bags still had healthy stems. These grapes also lost the least amount of water $(1.35 \%)$. In all cases, cluster bags reduced water losses during postharvest cold storage (table 4).

Air temperatures during the trials ranged from $71^{\circ} \mathrm{F}$ to $98^{\circ} \mathrm{F}$. In general, grapes that were harvested in the morning (7 AM) were taken to the cold storage at $11 \mathrm{AM}$ (4-hour cooling delay) or at 3 PM (8-hour cooling delay). Grapes from the afternoon delayed cooling period were harvested at $11 \mathrm{AM}$ and then taken to the cold storage at 3 PM. Air temperatures during the morning delayed cooling period ranged from $71^{\circ} \mathrm{F}$ to $91^{\circ} \mathrm{F}$. Air temperatures during the afternoon delayed cooling period ranged from $84^{\circ} \mathrm{F}$ to $98^{\circ} \mathrm{F}$ (fig. 1 ). In general, air temperature during the three trials did not vary much between dates. However, there were air temperature differences of up to $24^{\circ} \mathrm{F}$ between the morning and afternoon.

The fact that grape stem browning is caused by low levels of cluster/ stem water loss and that the potential for high levels of water loss exist during our standard harvesting operations points out the importance of minimizing cooling delays. One practical approach to limit water losses may be the use of restricted cluster bags and/or box liners. In our previous work (Crisosto et al. 1994), we recommended the use of a perforated box liner with or without an $\mathrm{SO}_{2}$ pad as one successful technique to reduce water loss during field packing and postharvest handling of grapes for export or longterm storage. We are currently developing a restricted cluster bag with a vented area of $0.5 \%$ to $1.2 \%$. Ideally, we would like to develop a restricted cluster bag and/or perforated box liner that reduces water loss without significantly increasing cooling time or interfering with sulfur dioxide fumigation.

\section{Recommendations}

Based on our work and other studies previously published (Nelson
1985), we recommend the following practices to reduce stem browning:

- Pick, pack and transport grapes to the cold storage as soon as possible.

- Rapidly cool grapes as soon as possible after harvest.

- Pay close attention to the first 8 hours of grape postharvest life.

- Ideally, harvest Flame Seedless for long-term storage only during the morning.

- It is essential to provide good management and supervision during the harvest and postharvest handling.

- Cover or place grapes in the shade if harvested grapes are temporarily stored in the vineyard.

- Use forced-air initial fumigation in combination with cooling.

- Remove the fruit from the precooler as soon as the fruit reaches the desired temperature in the warmest position (or just turn the fan off).

- Store grapes at $31.5^{\circ} \mathrm{F}$ to $32^{\circ} \mathrm{F}$ pulp temperature throughout their postharvest life.

- Measure and record product temperatures during loading.

- Check loading patterns used during transportation.

C.H. Crisosto is Postharvest Physiologist, Department of Pomology, UC Davis, and N.K. Dokoozlian is Extension Viticulturist, Department of Viticulture and Enology, UC Davis, both located at UC Kearney Agricultural Center, Parlier; and J.L. Smilanick is Researcher Plant Pathologist, U.S. Department of Agriculture, Agricultural Research Station, Fresno.

\section{References}

Crisosto $\mathrm{CH}$, Smilanick JL, Dokoozlian NK, Luvisi DA. 1994. Maintaining table grape post-harvest quality for long distance markets. International Symposium on Table Grape Production, June 28 \& 29, 1994 , American Society for Enology and Viticulture, p 195-9.

Cappellini RA, Ceponis MJ, Lightner GW. 1986. Disorders in table grape shipments to the New York market, 1972-1984. Plant Disease 70:1075-9.

Nelson KE. 1985. Harvesting and handling California table grapes for market. UC Bulletin 1913. Oakland, CA: ANR Publications. 72 p. 